\title{
Microstructure Changes in Autoclaved Aerated Concrete during Carbonation under Working and Accelerated Conditions
}

\author{
Fumiaki Matsushita $^{1}$, Yoshimichi Aono ${ }^{2}$ and Sumio Shibata ${ }^{3}$
}

Received 4 July 2003, accepted 17 December 2003

\begin{abstract}
The microstructure of AAC changes during carbonation, resulting in degradation such as cracking. AAC panels under working conditions (Field-AAC) aged 5 to 33 years and AAC blocks carbonated under accelerated conditions (Labo-AAC) were subjected to microstructural analysis. The degree of carbonation increased with time and approached $60 \%$ both under working and accelerated conditions. Changes of micro-level structures such as surface and crystal structures were more significant under accelerated conditions than under working conditions. Meso-level structures such as the interparticle pore volume were similar regardless of the carbonation conditions. The increase in drying shrinkage was more significant under accelerated conditions than under working conditions because it originated not only from the moisture characteristics but also the micro-level structures.
\end{abstract}

\section{Introduction}

Autoclaved aerated concrete (AAC) has been produced in great quantities over the past 70 years all over the world. Therefore, the durability and service life of AAC have now become subjects of urgent study. One of the most effective factors affecting the durability of AAC is carbonation, in which Tobermorite- $1.1 \mathrm{~nm}\left(5 \mathrm{CaO} \cdot 6 \mathrm{SiO}_{2} \cdot 5 \mathrm{H}_{2} \mathrm{O}\right)$, the main binding mineral of $\mathrm{AAC}$, reacts with atmospheric carbon dioxide gas in the presence of moisture, and is decomposed to silica-gel and calcium carbonate:

$$
\begin{aligned}
& 5 \mathrm{CaO} \cdot 6 \mathrm{SiO}_{2} \cdot 5 \mathrm{H}_{2} \mathrm{O}+5 \mathrm{CO}_{2} \\
& \longrightarrow 5 \mathrm{CaCO}_{3}+6 \mathrm{SiO}_{2} \cdot \mathrm{nH}_{2} \mathrm{O}+(5-\mathrm{n}) \mathrm{H}_{2} \mathrm{O}
\end{aligned}
$$

Carbonation of ordinary concrete is a reaction of $\mathrm{CSH}-$ gel and calcium hydroxide with carbon dioxide gas, which leads to the loss of alkalinity and rust resistance. This is why neutralization is the foremost requirement in the case of ordinary concrete carbonation.

On the other hand, the main binding mineral of AAC is Tobermorite- $1.1 \mathrm{~nm}$, which is originally neutral or weakly alkaline, because AAC is cured in the autoclave at a temperature of approximately $180^{\circ} \mathrm{C}$ and a pressure of 10 atms for a sufficiently long duration, regardless of the raw materials such as quartz sand, cement, calcium oxide, slag and disposed AAC powders. The reinforcing steel in AAC is coated with rust-resistant materials before casting because Tobermorite- $1.1 \mathrm{~nm}$ has no rust-preventive capability (RILEM 1993). Therefore, the

\footnotetext{
${ }^{1}$ Researcher, R\&D Center Mie Branch, Sumitomo Metal Mining Siporex Co., Ltd, Japan

E-mail: Fumiaki_Matsushita@ni.smm.co.jp

${ }^{2}$ Chief Researcher, R\&D Center, Sumitomo Metal Mining Siporex Co., Ltd , Japan

${ }^{3}$ General Manager, R\&D Center, Sumitomo Metal Mining Siporex Co., Ltd, Japan
}

issue in the case of AAC carbonation is not the issue of neutralization but the changes in the matrix itself. During carbonation, not only changes in minerals but also changes in microstructure leading to degradation such as decrease in strength, shrinkage and, especially, increase in lattice-like cracking occur. This is why so many studies have been devoted to changes in microstructure during carbonation.

Sauman $(1971,1972)$ studied the changes in compressive strength, carbonation shrinkage and the 'pseudomorphism' shape-changes of Tobermorite- $1.1 \mathrm{~nm}$ crystals. It was shown that only the marginal parts of the crystal were somewhat frayed and unsharpened under accelerated conditions ranging from 1 to 30 vol.\% of $\mathrm{CO}_{2}$ and from 50 to $100 \% \mathrm{RH}$. Sun et al. (1985) observed 3 types of AAC samples made of different raw materials under SEM after accelerated carbonation of 50 vol. $\%$ of $\mathrm{CO}_{2}$ and $50 \% \mathrm{RH}$. They suggested that calcium carbonate deposited on the walls of air pores, while silica-gel maintained the original network structure of Tobermorite- $1.1 \mathrm{~nm}$, and these changes were not different among samples. Iwasaki and Tada (1985) showed the changes in pore volume proportions, distinguishing between submicro-, meso- and macro-pores by means of water vapor sorption isotherms and mercury porosimeter for accelerated carbonated AAC under conditions of 20 vol.\% of $\mathrm{CO}_{2}$ and $100 \%$ RH. Ikeda et al. (1991) indicated that the silicate structures in Tobermorite- $1.1 \mathrm{~nm}$ were changed from double-chain structures to 3 -dimensional framework structures by means of ${ }^{29} \mathrm{Si}$ MAS NMR spectrum after accelerated carbonation conditions of 10 vol. $\%$ of $\mathrm{CO}_{2}$ and $60 \% \mathrm{RH}$. However, these studies also examined AAC carbonated under accelerated conditions without correlating the carbonation under working conditions.

Several studies on carbonation under working conditions have been reported. Hanecka et al. (1997) showed an increase in density. Dapkus and Stankevicius (1985) 
showed an increase in the amount of water content by carbonation. However, the microstructure changes of AAC under working conditions, which are extremely important for determining durability and service life, have not been investigated. It is also very important to clarify the difference between changes in the microstructure of AAC carbonated under working and accelerated conditions for the prediction of degradation and remaining life by means of accelerated carbonation methods.

We will discuss the changes in three different microstructures of AAC carbonated under working and accelerated conditions with reference to Wittmann (1983, 1985). Wittmann (1983) pointed out the necessity of different structural pore levels to understand the mechanical properties of concrete. On the micro-level, the internal surface and crystal structures of tobermorite are characterized. The meso-level is superior to the micro-level because all the processes described on the micro-level are reflected on the meso-level, but additional aspects have to be added on the meso-level before the results of the micro-level become relevant for the composite materials behavior. Characteristic features of the meso-level are large pores and inclusions. Finally, the composite structure is taken as a quasi-homogeneous on the macro-level.

\section{Experimental}

\subsection{Specimens}

Three types of AAC were subjected to analysis: AAC panels under working conditions (Field-AAC) with ages from 5 to 33 years, laboratory-carbonated AAC blocks (Labo-AAC), and non-treated AAC blocks (Nontreated-AAC).

Ordinary AAC blocks made by Sumitomo Metal Mining Siporex Co., Ltd were used for Nontreated-AAC. The chemical composition and $\mathrm{N}_{2}$-BET specific surface area are shown in Table 1.

The same ordinary AAC blocks were also used for Labo-AAC. They were shaped in sets of $100 \times 40 \times 10$ $\mathrm{mm}, 100 \times 100 \times 100 \mathrm{~mm}$ and $40 \times 40 \times 160 \mathrm{~mm}$ to be suitable for experiments after carbonation. Subsequently, they were dried at $105^{\circ} \mathrm{C}$ for 2 hours and were pre-treated at $90 \% \mathrm{RH}$. and a temperature of $20^{\circ} \mathrm{C}$ for 1 week. Afterwards, they were treated under accelerated carbonation conditions of 3 vol. $\%$ of $\mathrm{CO}_{2}, 90 \% \mathrm{RH}$. and a temperature of $20^{\circ} \mathrm{C}$ for 50 days in a carbonation chamber.

Field-AACs were sampled from several buildings in Japan. The normal climate in Japan is 0.03 vol.\% of $\mathrm{CO}_{2}, 25$ to $95 \% \mathrm{RH}$. and temperature of 0 to $35^{\circ} \mathrm{C}$.

Table 1 Chemical composition and BET specific surface area for Nontreated-AAC.

\begin{tabular}{|c|c|c|c|c|c|c|}
\hline \multicolumn{6}{|c|}{ Chemical composition (mass\%) } & \multirow[t]{2}{*}{ N2-BET $\left(\mathrm{m}^{2} / \mathrm{g}\right)$} \\
\hline $\mathrm{SiO}_{2}$ & $\mathrm{CaO}$ & $\mathrm{Al}_{2} \mathrm{O}_{3}$ & $\mathrm{Fe}_{2} \mathrm{O}_{3}$ & $\mathrm{SO}_{3}$ & Ig-Loss & \\
\hline 52.9 & 27.5 & 2.56 & 1.47 & 4.52 & 10.4 & 20.4 \\
\hline
\end{tabular}

All specimens were dried at $105^{\circ} \mathrm{C}$ for 2 hours before experiments. They were ground sufficiently for instrumental analysis and were shaped to dimensions of $100 \times$ $100 \times 100 \mathrm{~mm}$ for measuring bulk density and $40 \times 40$ $\times 160 \mathrm{~mm}$ for measuring length changes, fixing a pair of $20 \mathrm{~mm}$ brass pins fixed on both ends with an adhesive.

\subsection{Measurement of degree of carbonation}

The amounts of combined carbon dioxide and calcium oxide were measured to determine the degree of carbonation (Matsushita et al. 2000). TG-DTA was used for analysis of the amount of combined carbon dioxide excluding both the amount of adsorbed carbon dioxide gas and carbonated salt other than calcium carbonate. The weight loss during the $600-800^{\circ} \mathrm{C}$ in DTA-TG curve was estimated at the carbon dioxide absorption. The amount of calcium oxide was analyzed by ICP. The degree of carbonation $(D c)$ can be expressed with the following equation

$$
\operatorname{Dc}(\%)=\left[\left(C-C_{0}\right) /\left(C_{\max }-C_{0}\right) \times 100\right],
$$

where $C, C_{0}$ and $C_{\max }$ are the amount of combined carbon dioxide in a measured sample, in the Nontreated-AAC and in the AAC when all calcium oxide becomes calcium carbonate.

\subsection{Analysis of crystalline phases and micro- structure}

Crystalline phases were analyzed by XRD using RIGAKU RINT 1000 with $\mathrm{CuK} \alpha$ radiation under the conditions of $40 \mathrm{kV}$ and $30 \mathrm{~mA}$. The microstructure was analyzed by mercury porosimeter, EPMA, SEM, $\mathrm{N}_{2}$ BET specific surface area analyzer, water vapor sorption isotherms and ${ }^{29} \mathrm{Si}$ MAS NMR. Mercury porosimetry was measured with Shimadzu autopore 9200. EPMA cross section analysis of $\mathrm{Si}$ and $\mathrm{Ca}$ were measured with Shimadzu EPMA-2300. Jeol JSM-5410 was used for SEM observation. The $\mathrm{N}_{2}$ BET specific surface area was measured by Carlo Erba Strumentazione Sorptomatic-1800. Water vapor sorption isotherms were measured by automatic sorption apparatus BERSORP-18. ${ }^{29} \mathrm{Si}$ MAS NMR spectra were recorded by the JEOL JNM- $\Lambda$-400WB with an observation frequency of 79.42 $\mathrm{MHz}$, a repeating time of $7.0 \mathrm{~s}$, a contact time of $6.4 \mu \mathrm{s}$ and a cumulative number of 3000 to 12000 scans.

\subsection{Measurement of bulk density}

Bulk density, $\gamma$, of the specimen was determined (RILEM 1993) as follows:

$$
\gamma=M / V \quad\left(\mathrm{~kg} / \mathrm{m}^{3}\right)
$$

where $M=$ the mass of the dried out specimen $(\mathrm{kg})$ after oven drying at $105^{\circ} \mathrm{C}$ for a sufficiently long time and $V$ $=$ the specimen volume $\left(\mathrm{m}^{3}\right)$.

\subsection{Measurement of drying shrinkage}

Drying shrinkage was measured as a length change from the water saturated condition to the equilibrium state 
under $45 \%$ RH. The length of a $40 \times 40 \times 160 \mathrm{~mm}$ specimen with a pair of $20 \mathrm{~mm}$ brass pins fixed on both ends by an adhesive was measured by a digital-gauge with a minimum range of $0.001 \mathrm{~mm}$. A stainless standard length stick of $175 \mathrm{~mm}$ was used.

\section{Results and discussion}

\subsection{Degree of carbonation (Dc)}

Changes in Dc of the Field-AAC and the Labo-AAC as a function of time are shown in Figs. 1 (a) and (b), respectively. For the Field-AAC, Dc increased with the number of years of exposure and approached approximately $60 \%$ after 30 years. For the Labo-AAC, Dc increased with number of days of treatment and approached approximately $60 \%$ after 40 days. In the following discussion, Dc will be used as a basis of the evaluation of the changes in properties because the overall changes of Dc were very similar both in the Field-AAC and the Labo-AAC.

\subsection{Changes in crystalline phases}

The XRD patterns for the Nontreated-, Field- and Labo-AAC at various Dc are shown in Figs. 2 (a) and (b). For Nontreated-AAC, Tobermorite-1.1nm, $\alpha$-Quartz, Anhydrite $\left(\mathrm{CaSO}_{4}\right)$ and Bassanite $\left(\mathrm{CaSO}_{4} \cdot \frac{1}{2} \mathrm{H}_{2} \mathrm{O}\right)$ were found. For Field-AAC, Anhydrite was found only at Dc $=25 \%$ while Bassanite was not found any more and Gypsum $\left(\mathrm{CaSO}_{4} \cdot 2 \mathrm{H}_{2} \mathrm{O}\right)$ was found. In the working condition, Anhydrite and Bassanite may dissolve and re-crystallize to form Gypsum over period of many years. On the other hand, for Labo-AAC, Anhydrite and Bassanite remained present up to $\mathrm{Dc}=60 \%$. In acceler-

(a)

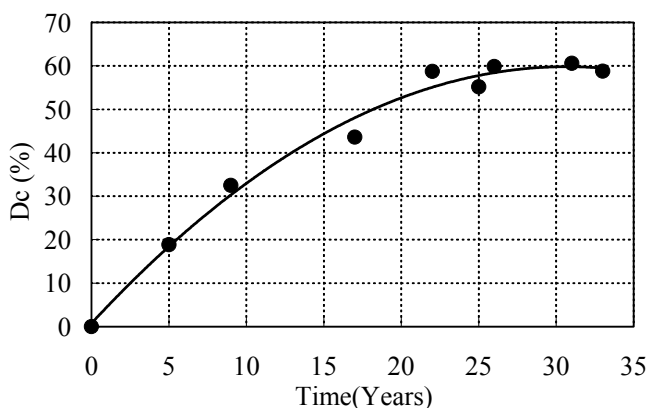

(b)

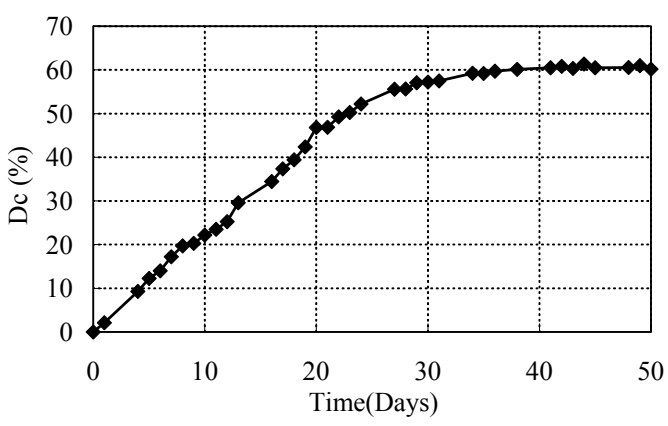

Fig. 1 Degree of Carbonation (Dc) of (a) Field-AAC and (b) Labo-AAC. ated carbonation conditions, the time may be too short for re-crystallization. Calcium carbonate was found as Calcite and Vaterite both in Field- and Labo-AAC. The XRD peak intensities of Tobermorite- $1.1 \mathrm{~nm}(002,2 \theta=$ $\left.7.8^{\circ}\right)$, Calcite $\left(110,2 \theta=35.95^{\circ}\right)$ and Vaterite $(102,2 \theta=$ $32.71^{\circ}$ ) for the Field- and Labo-AAC are shown in Figs. 3 (a) and (b), respectively. In all samples, Tobermorite-1.1nm decreased and Calcite increased with an increase of Dc, and Vaterite began to increase at a Dc approximately $30 \%$. Therefore, the decomposition of Tobermorite- $1.1 \mathrm{~nm}$ and the deposition of calcium carbonate were similar in each type of AAC though the carbonation rate was different due to the differences in atmospheric carbon dioxide concentration and relative humidity.

\subsection{Changes in micro-level structures}

Figure 4 shows the changes in the $\mathrm{N}_{2}$ BET specific surface area. For the Labo-AAC, the $\mathrm{N}_{2}$ BET specific surface area increased from approximately 20 to $60 \mathrm{~m}^{2} / \mathrm{g}$ during carbonation. For the Field-AAC, however, it decreased to approximately $10 \mathrm{~m}^{2} / \mathrm{g}$. The pore size distributions by $\mathrm{N}_{2}$ desorption isotherms are shown in Figs. 5 (a) and (b). All ranges of micropores decreased by carbonation in the Field-AAC while the volume of micropores of approximately $1 \mathrm{~nm}$ increased drastically in the Labo-AAC. It is clear that the differences in pore

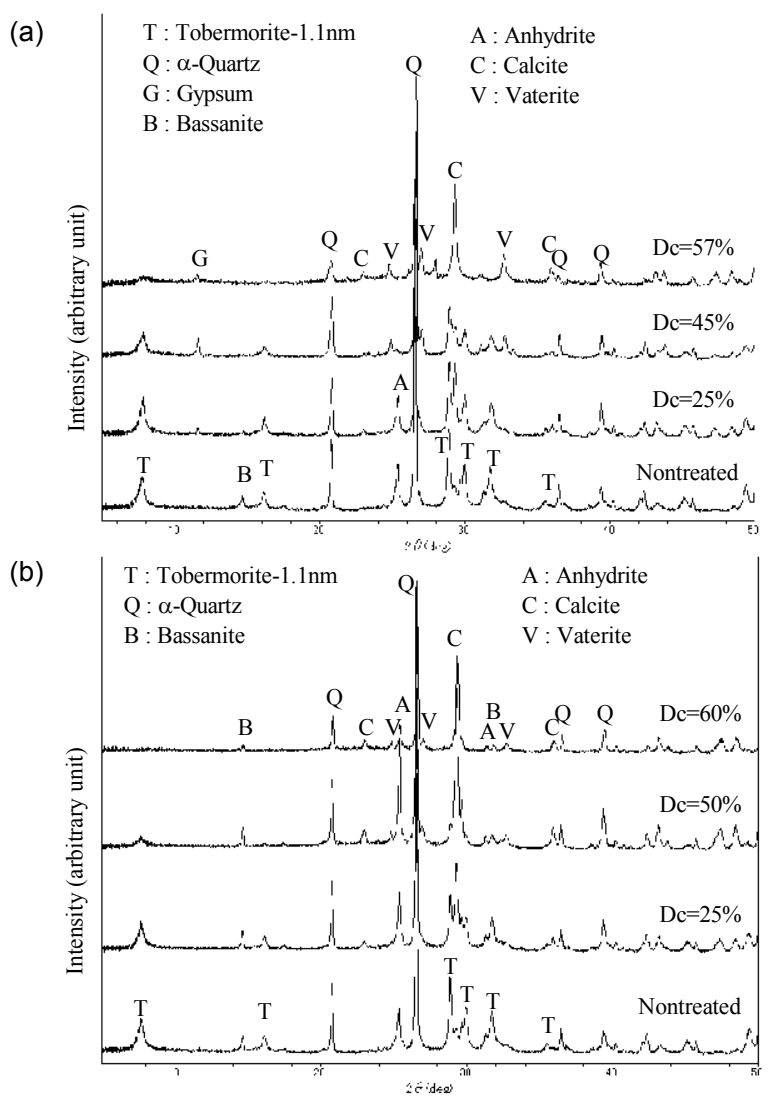

Fig. 2 XRD patterns for (a) Nontreated- and Field-AAC and (b) Nontreated- and Labo-AAC. 
(a)

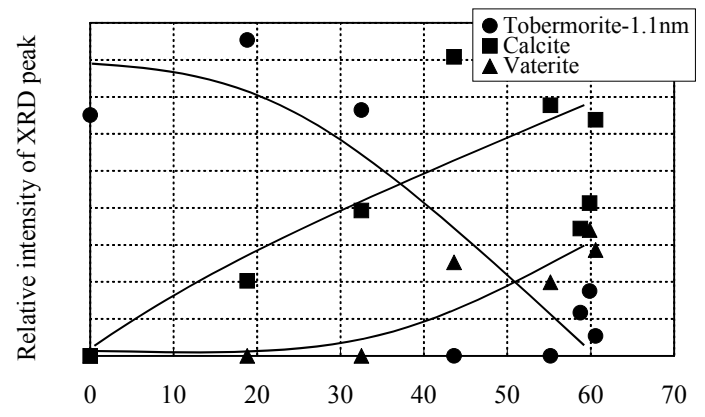

(b)

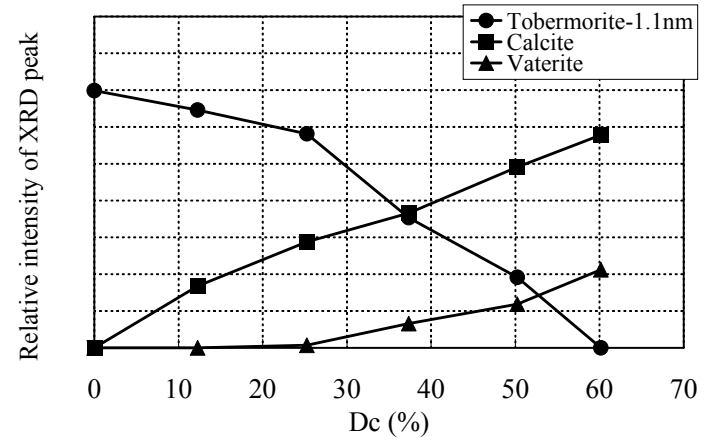

Fig. 3 XRD Peak Intensities of Tobermorite-1.1nm, Calcite and Vaterite for (a) Field-AAC and (b) Labo-AAC.

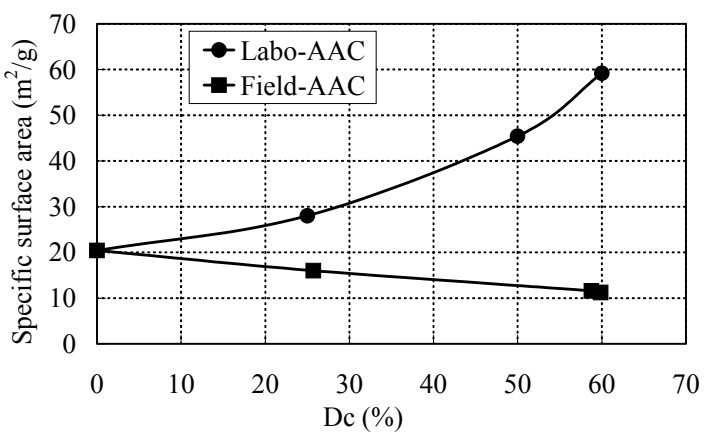

Fig. $4 \mathrm{~N}_{2}$ BET specific surface area.

structure around nanometer levels, which had a great influence upon the $\mathrm{N}_{2}$ BET specific surface area, corresponded with the differences in surface structures in silica gels between Field-AAC and Labo-AAC, because crystals of calcium carbonate must be large enough not to affect these structural pore changes.

Water vapor sorption isotherms of Nontreated-, Fieldand Labo-AAC are shown in Figs. 6 (a) and (b). The equilibrium moisture content was approximately the same for both and increased slightly when Dc reached $25 \%$ or $30 \%$, but increased remarkably when Dc reached $50 \%$ or $60 \%$. A remarkable hysteresis loop was observed only in Field-AAC of Dc $=50 \%$ and $60 \%$. This was the type B hysteresis loop classified by de Boer indicating pore structures of slit or parallel plane shape. It was supposed that silica-gels of Field-AAC after excessive carbonation might have had layered structures in which adsorption and desorption of water were available.
Figure 7 shows SEM images in air pores of Nontreated-AAC, Field-AAC (Dc $=60 \%)$ and Labo-AAC $(\mathrm{Dc}=60 \%)$. The shape of Tobermorite- $1.1 \mathrm{~nm}$ particles of the Nontreated-AAC is planer. In the carbonated samples, the plate-like crystals are no longer Tobermorite-1.1nm but the shape of silica-gels, which is called pseudomorphism, originated from de-

(a)

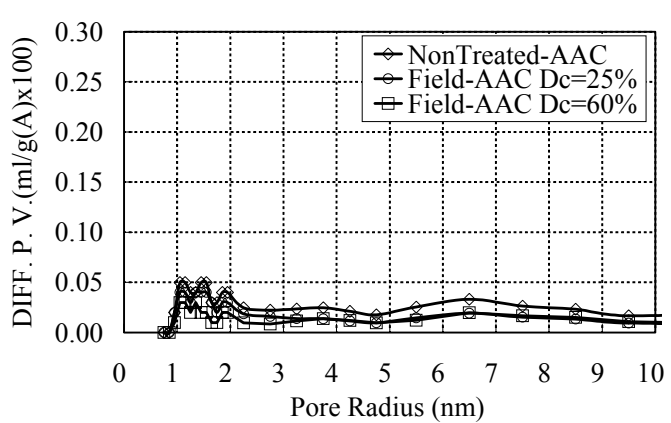

(b)

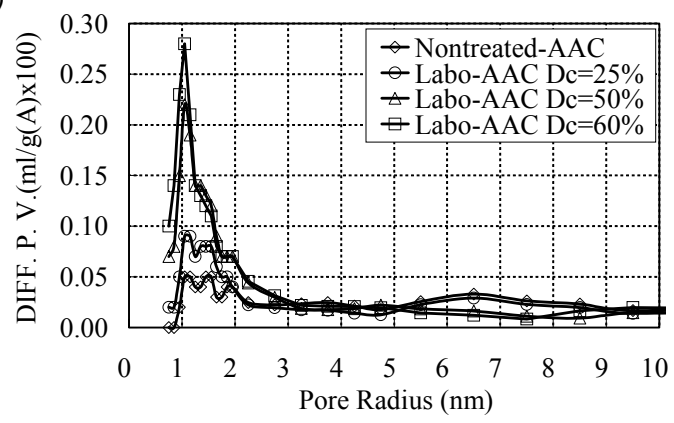

Fig. 5 Pore size distributions by $\mathrm{N}_{2}$ desorption isotherms for (a) Nontreated- and Field-AAC and (b) Nontreatedand Labo-AAC.
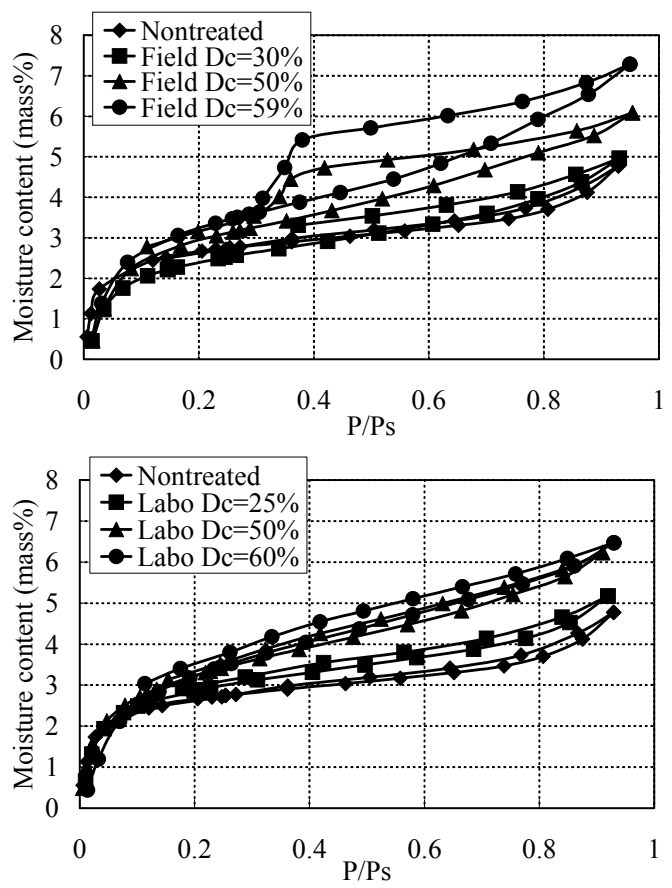

Fig. 6 Water vapor sorption isotherms for (a) Nontreatedand Field-AAC and (b) Nontreated- and Labo-AAC. 
(a)

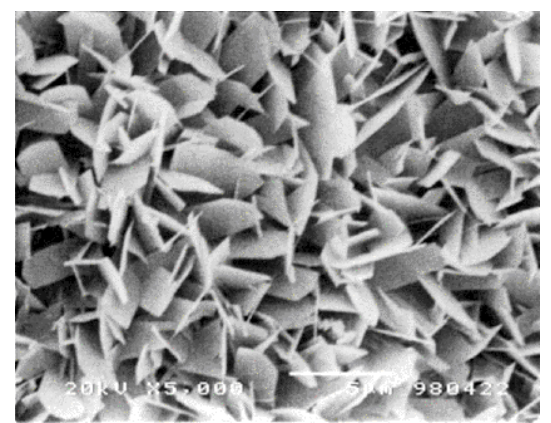

(b)

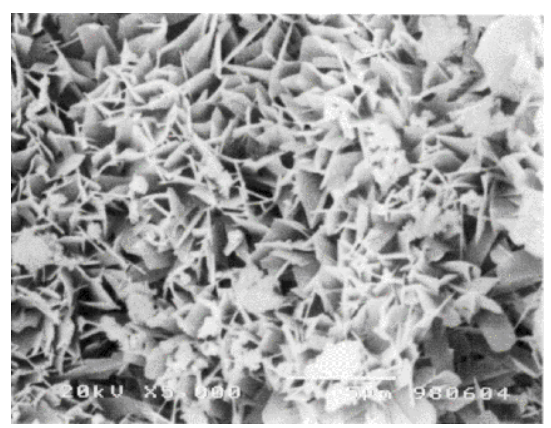

(c)

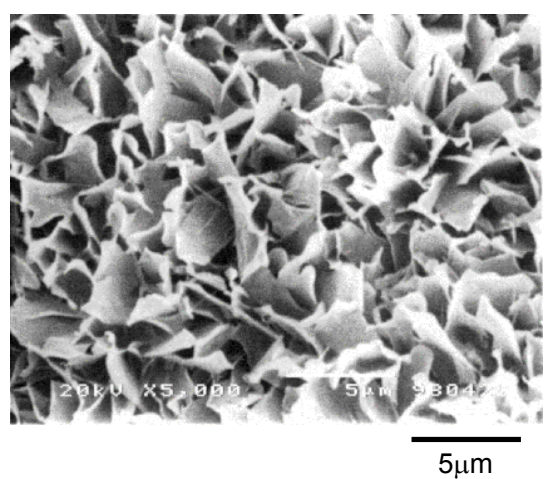

Fig. 7 SEM images in air pores for (a) Nontreated-AAC, (b) Field-AAC (Dc=60\%) and (c) Labo-AAC(Dc=60\%).

composed Tobermorite-1.1nm. For Labo-AAC, only the marginal parts of the silica-gels were somewhat frayed and unsharpened as shown in the preceding studies
(Sauman 1972). On the other hand, for Field-AAC, the shapes of silica-gels were similar to those of Tobermorite- $1.1 \mathrm{~nm}$ of Nontreated-AAC. On the whole, the planer particle shapes were not changed significantly during carbonation both under working and accelerated conditions. Calcium carbonate (calcite and vaterite) did not appear in the SEM images because its deposited crystals were too large to fit in high-magnification photographs, as shown in the next paragraph.

The ${ }^{29} \mathrm{Si}$ MAS NMR spectra of Nontreated-, Fieldand Labo-AAC are shown in Fig. 8. Chemical shifts of ${ }^{29} \mathrm{Si}$ MAS NMR are shown in Table 2. $\mathrm{Q}^{2}$ and $\mathrm{Q}^{3}$ spectrum of Nontreated-AAC corresponding to the silicate double-chain structures of Tobermorite-1.1nm were found to be in agreement with Wieker et al. (1982). The other peaks of $\mathrm{Q}^{2}$ and $\mathrm{Q}^{3}$ of the Field- and Labo-AAC approximately at $-83 \mathrm{ppm}$ and $-103 \mathrm{ppm}$, which corresponds to the protonated silicate ions, were found with an increase of Dc (Klur et. al 1997, Cong et. al 1993). $\mathrm{Q}^{4}$ spectra of the Labo-AAC, which correspond to the silicate 3-dimensional framework structures similar to ordinary silica-gels, were found at a final stage of carbonation as reported by Ikeda et al. (1991). However, the broad spectra around the $\mathrm{Q}^{3}$ position of the Field-AAC, which corresponds to the silicate sheet-like structures but has not been reported yet, were found at a final stage of carbonation.

Tobermorite- $1.1 \mathrm{~nm}$ has a layered structure in which silicate double-chain structures are sandwiched between $\mathrm{CaO}$ layers. Carbonation reaction of the Field-AAC was relatively slow and moderate because atmospheric carbon dioxide concentration was as low as 0.03 vol.\%. Therefore, it was observed that the silicate structures were rearranged slightly from a double-chain to a sheet-like structure and the crystals became bigger just like Ostwald Ripening during carbonation under working conditions. It was also observed in the Field-AAC that the layered structures of silica-gel was a result of the silicate sheet-like structures, and the planer particle shapes of Tobermorite- $1.1 \mathrm{~nm}$ remained unchanged ow-

Table $2{ }^{29}$ Si MAS NMR chemical shifts of samples.

\begin{tabular}{|c|c|c|c|c|c|c|c|c|c|}
\hline \multirow{2}{*}{$\begin{array}{l}\text { ppm from TMS } \\
\text { (Relative intensity) }\end{array}$} & \multirow{2}{*}{$\frac{\mathrm{Q}^{1}}{\mathrm{Q}^{1}}$} & \multicolumn{3}{|c|}{$\mathrm{Q}^{2}$} & \multicolumn{3}{|c|}{$\mathrm{Q}^{3}$} & \multicolumn{2}{|c|}{$\mathrm{Q}^{4}$} \\
\hline & & & & $\mathrm{Q}^{2}$ & $\mathrm{Q}^{3}(1 \mathrm{Al})$ & $\mathrm{Q}^{3}$ & & $\mathrm{Q}^{4}$ & $\mathrm{Q}^{4}(\mathrm{Quartz})$ \\
\hline Nontreated-AAC & $\begin{array}{c}-80.6 \\
(28) \\
\end{array}$ & & & $\begin{array}{c}-85.3 \\
(100)\end{array}$ & $\begin{array}{c}-92.0 \\
(16)\end{array}$ & $\begin{array}{c}-96.0 \\
(17)\end{array}$ & & & $\begin{array}{c}-107.4 \\
(4)\end{array}$ \\
\hline Field-AAC Dc $=25 \%$ & $\begin{array}{c}-79.8 \\
(12)\end{array}$ & $\begin{array}{c}-82.6 \\
(30)\end{array}$ & & $\begin{array}{c}-85.9 \\
(100)\end{array}$ & $\begin{array}{c}-92.2 \\
\text { (3) }\end{array}$ & $\begin{array}{c}-96.2 \\
(28)\end{array}$ & & & \\
\hline Field-AAC Dc $=50 \%$ & & $\begin{array}{c}-82.9 \\
(13)\end{array}$ & & $\begin{array}{c}-86.0 \\
(48)\end{array}$ & & $\begin{array}{c}-96.9 \\
(100)\end{array}$ & $\begin{array}{c}-103.9 \\
(60)\end{array}$ & & \\
\hline Field-AAC Dc $=60 \%$ & & & & $\begin{array}{c}-87.2 \\
(29) \\
\end{array}$ & $<$ & $\begin{array}{r}-9 \\
\quad(1 \\
\end{array}$ & 9 & $>$ & \\
\hline Labo-AAC Dc $=25 \%$ & $\begin{array}{l}-80.4 \\
(15)\end{array}$ & & $\begin{array}{l}-83.4 \\
(51)\end{array}$ & $\begin{array}{c}-86.1 \\
(100)\end{array}$ & $\begin{array}{c}-92.4 \\
(23)\end{array}$ & $\begin{array}{c}-96.5 \\
(42)\end{array}$ & $\begin{array}{c}-102.7 \\
(54)\end{array}$ & $\begin{array}{c}-111.3 \\
(48)\end{array}$ & $\begin{array}{c}-107.7 \\
(14)\end{array}$ \\
\hline Labo-AAC Dc $=50 \%$ & & $\begin{array}{c}-82.8 \\
(5)\end{array}$ & & $\begin{array}{c}-86.1 \\
(21)\end{array}$ & & $\begin{array}{c}-98.0 \\
(60)\end{array}$ & $\begin{array}{c}-102.3 \\
(90)\end{array}$ & $\begin{array}{c}-111.1 \\
(100)\end{array}$ & $\begin{array}{c}-107.7 \\
(15)\end{array}$ \\
\hline Labo-AAC $\mathrm{Dc}=60 \%$ & & & & & & & $\begin{array}{c}-102.8 \\
(100)\end{array}$ & $\begin{array}{c}-110.3 \\
(68)\end{array}$ & $\begin{array}{c}-107.5 \\
(5)\end{array}$ \\
\hline
\end{tabular}



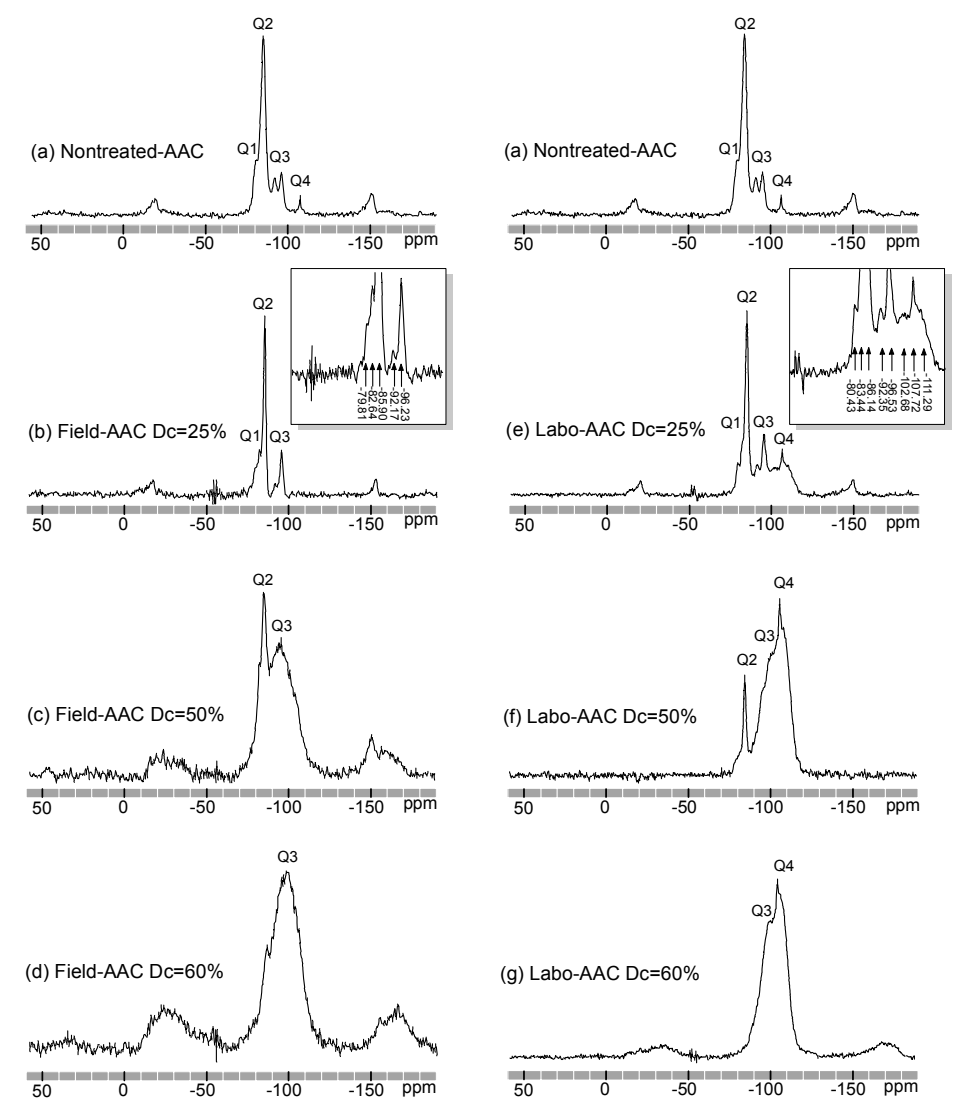

Fig. $8^{29}$ Si MAS NMR spectrum for Nontreated-AAC, Field-AAC and Labo- AAC.

ing to the moderate rearrangement of the silicate structures.

On the other hand, in the Labo-AAC, ambient carbon dioxide gas concentration was as high as 3 vol.\%, resulting in a very rapid and intensified carbonation reaction. Therefore, it was observed in the Labo-AAC that the silicate structures were extensively rearranged from double-chain to 3-dimensional framework structures, and the crystals were more finely divided, resulting in the increases of the $\mathrm{N}_{2}$ BET specific surface area and micropore volume at a pore diameter of approximately 1 $\mathrm{nm}$. It was also observed in the Labo-AAC that the marginal parts of the planer particle shape of Tobermorite- $1.1 \mathrm{~nm}$ were altered, i.e. somewhat frayed and unsharpened due to the considerable rearrangement of the silicate structures.

\subsection{Changes in meso-level structures}

Pore size distributions of the Nontreated-, Field- and Labo-AAC with different Dc by mercury porosimeter are shown in Figs. 9 (a) and (b). The total pore volume of the Field- and Labo-AAC decreased from $0.8 \mathrm{ml} / \mathrm{g}$ to $0.5 \mathrm{ml} / \mathrm{g}$ by carbonation, particularly in the characteristic pores of AAC of approximately 10 to $100 \mathrm{~nm}$ that correspond to the interparticle pores of Tobermorite-1.1nm. (Prim and Wittmann 1983)

Figure 10 shows $\mathrm{Ca}$ and $\mathrm{Si}$ distributions by EPMA cross-section analysis for the Nontreated-AAC as well as the Field- and Labo-AAC with different Dc. In these figures, "A" represents air pores, where both the $\mathrm{Si}$ and

(a)

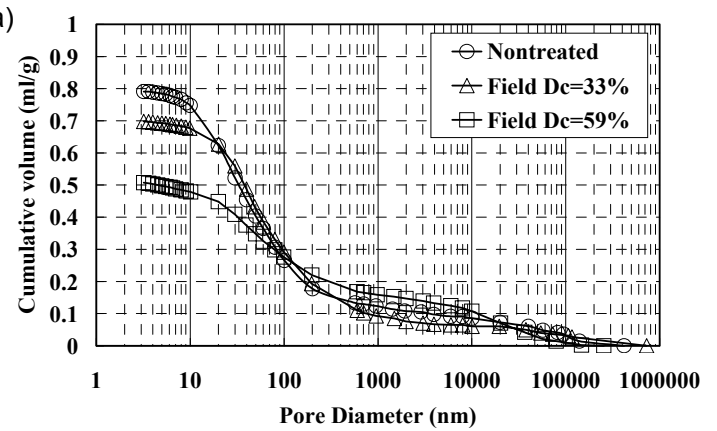

(b)

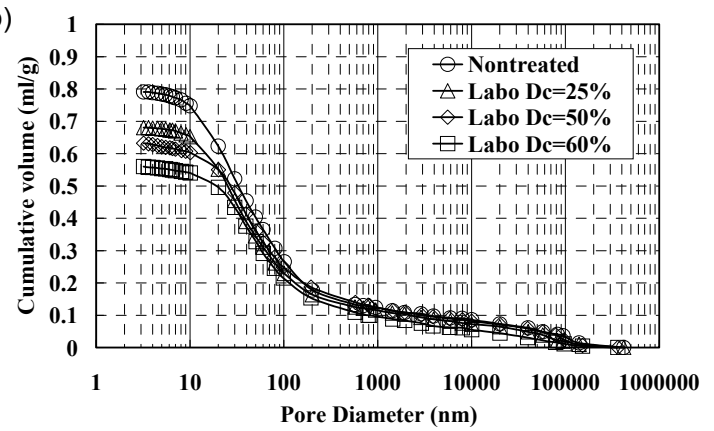

Fig. 9 Pore size distributions: (a) Nontreated- and Field-AAC; and (b) Nontreated- and Labo-AAC. 


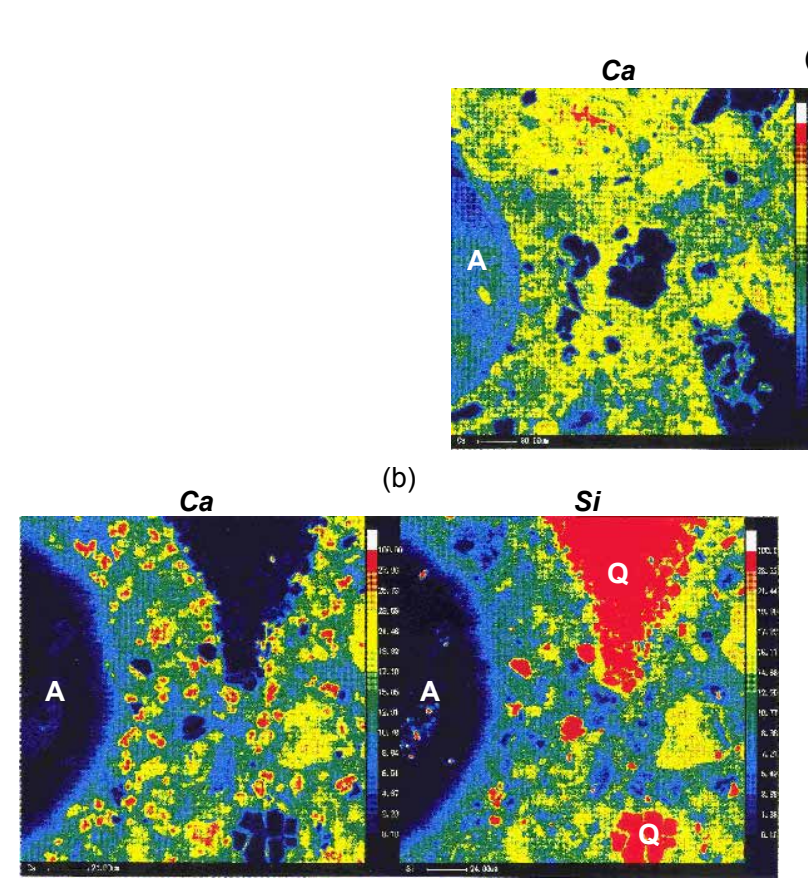

(c)

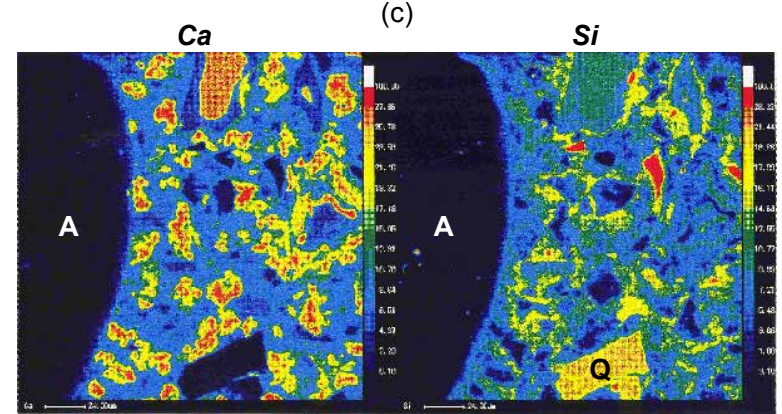

(d)

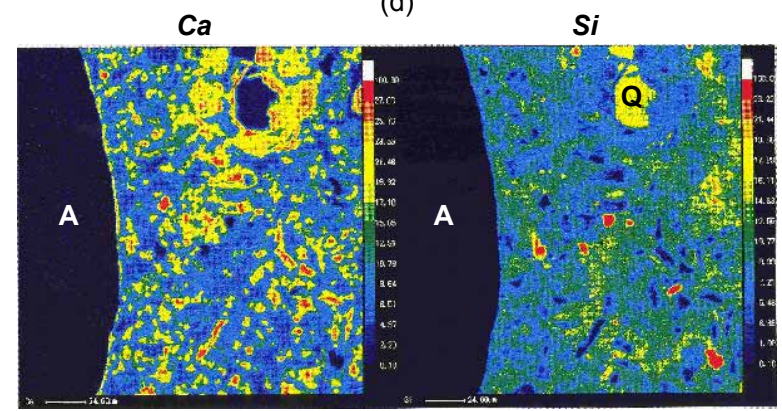

(a) Si

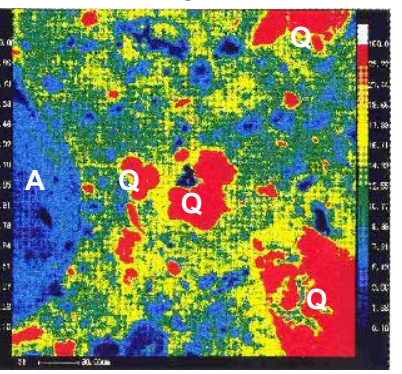

(e)

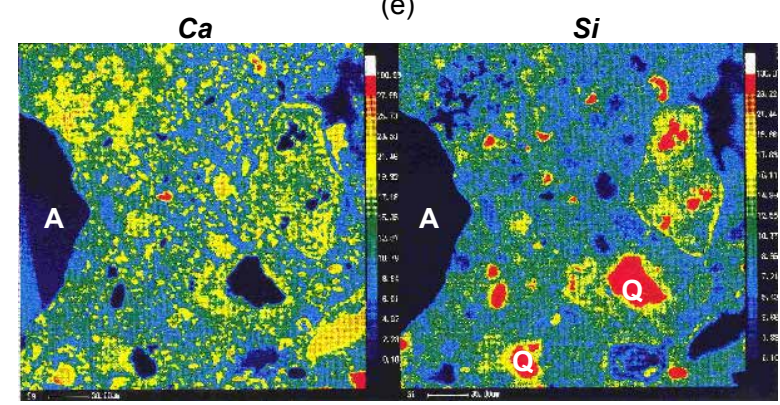

(f)
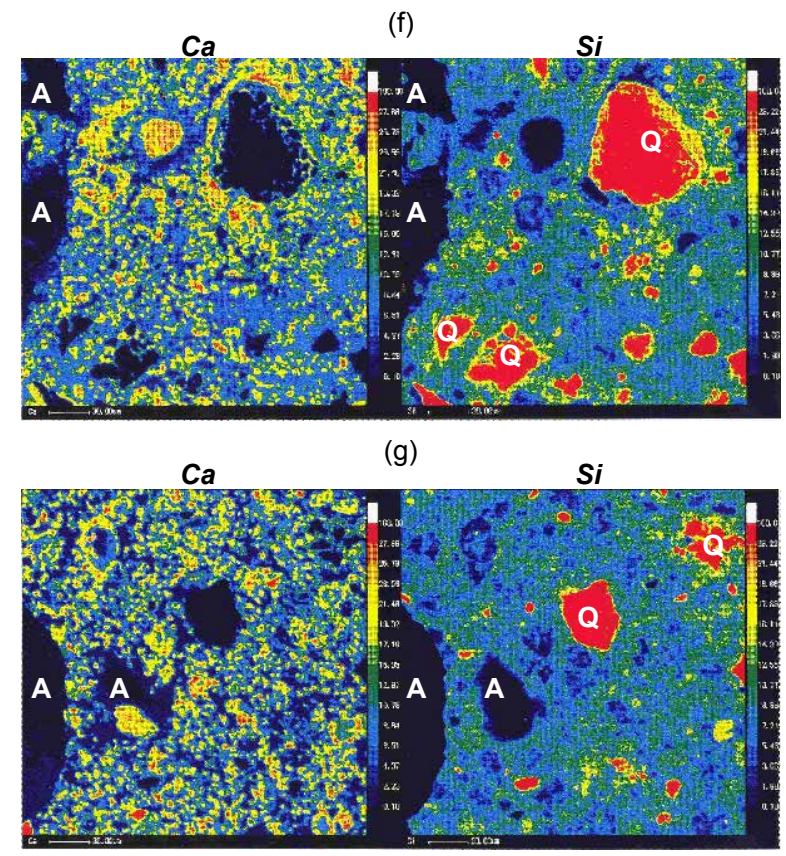

Fig. $10 \mathrm{Ca}$ and Si distributions by EPMA cross-section analysis: (a) Nontreated-AAC; (b) Field-AAC(Dc=25\%);

(c) Field-AAC(Dc=50\%); (d) Field-AAC(Dc=60\%); (e) Labo-AAC(Dc=25\%); (f) Labo-AAC(Dc=50\%) and

(g) Labo-AAC(Dc=60\%).

a distributions are shown in dark blue, and "Q" represents $\alpha$-Quartz particles, where the $\mathrm{Si}$ and $\mathrm{Ca}$ distributions are shown in red and dark blue, respectively. For the Nontreated-AAC, the Si distributions with yellow to blue and $\mathrm{Ca}$ distributions with yellow to green colors might represent the distribution frequencies of tobermorite platy particles as the distributions of these colors shows a resemblance. Therefore, $\mathrm{Ca}$ atoms and $\mathrm{Si}$ atoms were considered to be distributed homogeneously in the matrix unlike for $\alpha$-Quartz particles. The homogeneous distribution of $\mathrm{Ca}$ atoms in Nontreated-AAC shown in green and yellow changed to uneven distribution shown in red or yellow both in the Field-AAC and Labo-AAC, which suggests that $\mathrm{Ca}$ atoms were deposited cohesively in the matrix during carbonation. On the other hand, the distribution of $\mathrm{Si}$ atoms in the matrix, as shown in yellow, green and blue, was unchanged both in the Field-AAC and Labo-AAC. It was obvious that $\mathrm{Ca}$ ions were deposited from Tobermorite- $1.1 \mathrm{~nm}$ and reacted with carbon dioxide, while Si ions remained.

From the SEM images in Fig. 7, interparticle pores by geometrical arrangement of tobermorite particles are 


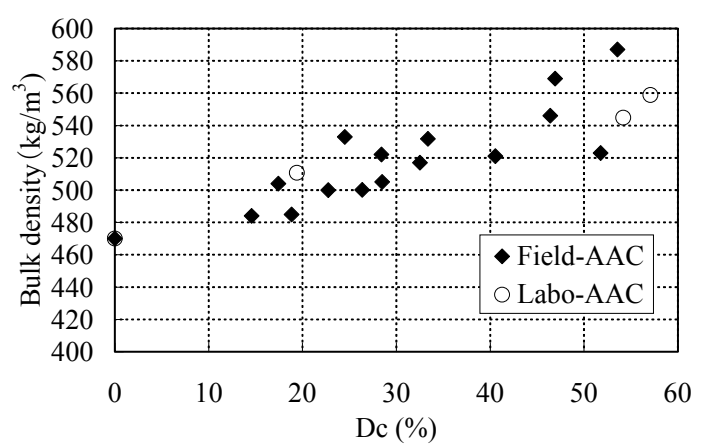

Fig. 11 Bulk density as a function of Dc.

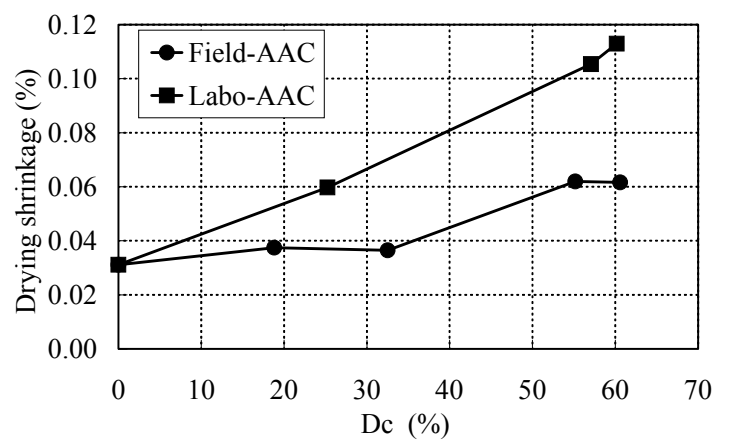

Fig. 12 Drying shrinkage as a function of Dc.

not changed significantly during carbonation both under working and accelerated conditions. Therefore, it is most likely that the decrease in pore volume during carbonation was the deposition of calcium carbonate into the interparticle pores at a pore diameter of approximately 10 to $100 \mathrm{~nm}$.

Changes in meso-level structure such as the interparticle pore volume and the deposition of calcium carbonate were almost similar regardless of the carbonation conditions.

\subsection{Changes of macro-level structures and drying shrinkage}

Quasi-homogeneous macro-level structures such as the ratio of air pores and matrix of course remained unchanged during carbonation. Bulk density as a function of Dc is shown in Fig. 11. Bulk density increased in proportion to the degree of carbonation in agreement with Hanecka et al. (1997) because carbon dioxide gas was fixed in AAC, forming a calcium carbonate.

Figure 12 shows drying shrinkage as a function of Dc. Drying shrinkage increased with the increase in Dc, from $0.03 \%$ to $0.06 \%$ and $0.11 \%$ for the Field-AAC and the Labo-AAC, respectively. Houst et al. (1983) pointed out that the hygral length change of AAC is linearly coupled with the change in surface energy and the additional expansion is caused by disjoining pressure at a higher RH. However they measured the drying shrinkage only for a fresh AAC. Drying shrinkage of carbonated $\mathrm{AAC}$ in this paper must be the result of the shrinkage of Tobermorite- $1.1 \mathrm{~nm}$ or silica-gels, which are the main binding minerals of Nontreated-AAC and carbon- ated AAC. Therefore, it was most likely that the increase in drying shrinkage was mainly due to the change in the main binding mineral from Tobermorite- $1.1 \mathrm{~nm}$ to silica-gels. It was also observed that changes in the silica-gel structure in the Labo-AAC were more pronounced than in the Field-AAC, while the equilibrium moisture content was nearly the same for both. Therefore, the drying shrinkage of the Labo-AAC was greater than that of the Field-AAC. In other words, macro-level behavior such as drying shrinkage originated not only from the moisture characteristics but also the micro-level structure such as the surface and crystalline structures.

\section{Conclusions}

Microstructure changes during carbonation of AACs under working conditions and accelerated conditions were investigated. The results can be summarized as follows.

(1) The degree of carbonation (Dc) increased with time and approached approximately $60 \%$ after 30 years and 40 days for AAC under working conditions and accelerated conditions, respectively.

(2) Tobermorite- $1.1 \mathrm{~nm}$ decreased and calcite increased with an increase of Dc and vaterite began to increase at a Dc of approximately $30 \%$ for both working and accelerated conditions.

(3) Changes in micro-level structures such as surface and silicate-chain structures detected by $\mathrm{N}_{2}$ BET, water vapor sorption isotherms and ${ }^{29} \mathrm{Si}$ MAS NMR were more significant under accelerated conditions than under working conditions.

(4) Meso-level structures such as the interparticle pore volume were almost similar regardless of the carbonation conditions.

(5) Increase of drying shrinkage was more significant under accelerated conditions than under working conditions. Macro-level behavior such as drying shrinkage was originated not only from the moisture characteristics but also the micro-level structure such as the surface and crystalline structures.

\section{Acknowledgments}

The authors are grateful to Prof. K. Okada and Dr. Y. Kameshima of the Tokyo Institute of Technology, for their support in the measurement of water vapor sorption isotherms.

\section{References}

Cong, X.-D., Kirkpatrick, R. J. and Diamond, S. (1993). ${ }^{\prime 29} \mathrm{Si}$ MAS NMR Spectroscopic investigation of alkali silica reaction product gels." Cement and Concrete Research, 23 (4), 811-823.

Dapkus, G. and Stankevicius, V. (1985). "Cellular concrete carbonation." Building Research and Practice, 13, 184-187.

Hanecka, K., Koronthalyova, O. and Matiasovsky, P. 
(1997). "The carbonation of autoclaved aerated concrete." Cement and Concrete Research, 27, 589-599.

Houst, Y, Alou, F. and Wittmann, F. H. (1983). "Influence of moisture content on mechanical properties of autoclaved aerated concrete." Autoclaved Aerated Concrete-Moisture and Properties, Ed. Wittmann, F. H., Elsevier, Amsterdam, 219-234.

Ikeda, Y., Yasuike, Y. and Takashima, Y. (1991). "29Si MAS NMR study on structurral change of silicate ions in tobermorite with carbonation of ALC." Journal of the Ceramics Society of Japan, 99, 423-426.

Iwasaki, M. and Tada, S. (1985). "Carbonation of aerated concrete." Proc. 1st Int. Symp. Cem. Concr., Beijing, 3, 414-423.

Klur, I., Pollet, B., Virlet, J. and Nonat, A. (1997). "C-S-H structure evolution with calcium content by multinuclear NMR." Nuclear Magnetic Resonance Spectroscopy of Cement-Based Materials, Ed. Colombet, P., Grimmer, A.-R., Zanni, H. and Sozzani, P., Springer, Berlin, 119-141.

Komarneni, S., Roy, R., Roy, D. M., Fyfe, C. A. and Kennedy, G. J. (1985). "Al-substituted tobermorite -the coordination of aluminum as revealed by solid-state 27Al magic angle spinning (MAS) NMR." Cement and Concrete Research, 15, 723-728.

Matsushita, F., Aono, Y. and Shibata, S. (2000). "Carbonation degree of autoclaved aerated concrete."
Cement and Concrete Research, 30, 1741-1745.

Prim, P. and Wittmann, F. H. (1983). "Structure and water absorption of aerated concrete.", Autoclaved Aerated Concrete-Moisture And Properties, Ed. Wittmann, F. H., Elsevier, Amsterdam, 55-69.

RILEM, (1993). "Autoclaved aerated concrete; properties, testing and design." Ed. Aroni, S., de Groot, G. J., Robinson, M. J., Svanholm G. and Wittman, F. H., E\&FN Spon, London.

Sauman, Z. (1971). "Carbonation of porous concrete and its main binding components." Cement and Concrete Research, 1, 645-662.

Sauman, Z. (1972). "Effect of $\mathrm{CO}_{2}$ on porous concrete." Cement and Concrete Research, 2, 541-549.

Sun, G., Tang, D. and Zhao, Y. (1985). "The carbonation of autoclaved aerated concrete and its hydration products." Proc. 1st Int. Symp. Cem. Concr., Beijing, 3, 331-342

Wieker, W., Grimmer, A.-R., Winkler, A., Magi, M., Tarmak, M. and Lippmaa, M. (1982). "Solid-state high-resolution ${ }^{29} \mathrm{Si}$ NMR Spectroscopy of synthetic $14 \AA, 11 \AA$ and $9 \AA$ tobermorites." Cement and Concrete Research, 12, 333-339.

Wittmann, F. H. (1983). "Structure and mechanical properties of concrete." Touhokudaigaku Kenchikugakuhou, Touhoku Univ., Japan, 22, 93-112.

Wittmann, F. H. (1985). "Structure of concrete and crack formation." Fracture of Non-Metallic Materials, Ed. Hermann, K. P. and Larsson, L. H., 309-340. 